\title{
Safety and Effectiveness of Cataract Surgery with Simultaneous Intravitreal Anti-VEGF in Patients with \\ Previously Treated Exudative Age-Related Macular Degeneration
}

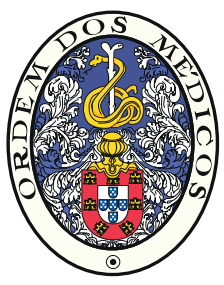

\section{Eficácia e Segurança da Cirurgia de Catarata Associada a Injecção Intravítrea de Anti-VEGF em Doentes com Degenerescência Macular Exsudativa Relacionada com a} Idade

\author{
Manuel Sousa FALCÃO $\rrbracket^{1,2}$, Paulo FREITAS-COSTA ${ }^{1,3}$, João Nuno BEATO ${ }^{1,2}$, João PINHEIRO-COSTA ${ }^{1,3}$ \\ Amândio ROCHA-SOUSA ${ }^{1,2}$, Ângela CARNEIRO ${ }^{1,2}$, Elisete Maria BRANDÃO ${ }^{2}$, Fernando FALCÃO-REIS Fi, $^{1,2}$ \\ Acta Med Port 2017 Feb;30(2):127-133 - http://dx.doi.org/10.20344/amp.7850
}

\section{ABSTRACT}

Introduction: To evaluate the safety and impact on visual acuity, retinal and choroidal morphology of simultaneous cataract surgery and intravitreal anti-vascular endothelial growth factor on patients with visually significant cataracts and previously treated exudative age-related macular degeneration.

Material and Methods: Prospective study, which included 21 eyes of 20 patients with exudative age-related macular degeneration submitted to simultaneous phacoemulsification and intravitreal ranibizumab or bevacizumab. The patients were followed for 12 months after surgery using a pro re nata strategy. Visual acuity, foveal and choroidal thickness changes were evaluated 1, 6 and 12 months post-operatively.

Results: There was a statistically significant increase in mean visual acuity at one (13.4 letters, $p<0.05)$, six (11.5 letters, $p<0.05)$ and twelve months $(11.3$ letters, $p<0.05)$ without significant changes in retinal or choroidal morphology. At 12 months, $86 \%$ of eyes were able to maintain visual acuity improvement. There were no significant differences between the two anti-vascular endothelial growth factor drugs and no complications developed during follow-up.

Discussion: Simultaneous phacoemulsification and intravitreal anti-vascular endothelial growth factor is safe and allows improvement in visual acuity in patients with visually significant cataracts and exudative age-related macular degeneration. Visual acuity gains were maintained with a pro re nata strategy showing that in this subset of patients, phacoemulsification may be beneficial.

Conclusion: Cataract surgery and simultaneous anti-vascular endothelial growth factor therapy improves visual acuity in patients with exudative age-related macular degeneration.

Keywords: Cataract Extraction; Macular Degeneration; Neovascularization; Phacoemulsification; Treatment Outcome; Vascular Endothelial Growth Factors

\section{RESUMO}

Introdução: Pretendemos avaliar a efectividade e segurança da cirurgia de catarata associada a injecção intravítrea de anti-vascular endothelial growth factor sobre a acuidade visual, morfologia da retina e coróide em doentes previamente tratados por degeneração macular relacionada com a idade exsudativa com cataratas visualmente significativas.

Material e Métodos: Estudo prospectivo, que incluiu 21 olhos de 20 doentes com degeneração macular relacionada com a idade exsudativa submetidos a facoemulsificação simultânea com ranibizumab ou bevacizumab intravítreo. Os doentes foram seguidos durante 12 meses após a cirurgia usando uma estratégia pro re nata. As alterações da acuidade visual, espessura da retina e coroideia subfoveal foram avaliadas aos 1, 6 e 12 meses de pós-operatório.

Resultados: Houve um aumento estatisticamente significativo da acuidade visual média ao mês $(13,4$ letras, $p<0,05)$, aos seis $(11,5$ letras, $p<0,05)$ e doze meses (11,3 letras, $p<0,05)$, sem alterações significativas na morfologia da retina ou coróide. Aos 12 meses, $86 \%$ dos olhos foram capazes de manter a melhoria da acuidade visual. Não houve diferenças significativas entre os dois fármacos anti-vascular endothelial growth factor e não ocorreu qualquer complicação durante o seguimento.

Discussão: A facoemulsificação associada a injecção intravítrea de anti-vascular endothelial growth factor é segura e permite uma melhoria da acuidade visual em doentes com degeneração macular relacionada com a idade exsudativa e cataratas visualmente significativas. O ganho de acuidade visual foi mantido usando uma estratégia pro re nata mostrando que neste subgrupo de doentes a facoemulsificação pode ser benéfica.

Conclusão: A cirurgia de catarata associada a terapia anti-vascular endothelial growth factor simultânea melhora a acuidade visual em doentes com degenerescência macular da idade exsudativa.

Palavras-chave: Degeneração Macular; Extração de Catarata; Facoemulsificação; Factores de Crescimento do Endotélio Vascular; Neovascularização; Resultado do Tratamento

1. Ophthalmology Department. Centro Hospitalar São João. Porto. Portugal.

2. Department of Sense Organs. Faculdade de Medicina. Universidade do Porto. Porto. Portugal.

3. Department of Anatomy. Faculdade de Medicina. Universidade do Porto. Porto. Portugal.

$\triangle$ Autor correspondente: Manuel Falcão. falcao@med.up.pt

Recebido: 15 de maio de 2016 - Aceite: 12 de setembro de 2016 | Copyright @ Ordem dos Médicos 2017 


\section{INTRODUCTION}

Age-related macular degeneration (AMD) and senile cataract are two age-related ocular pathologies that frequently coexist. In patients without retinal pathology, cataract surgery with intra-ocular lens implantation improves visual function. However, in patients with AMD, the implications of cataract surgery on retinal disease, namely a possible progression towards choroidal neovascularization (CNV) has greatly been debated. It is not clear at the present time if cataract surgery leads to AMD progression..$^{1-3}$ Some studies have shown this association ${ }^{4}$ whilst others have failed to do so. ${ }^{5}$ Most of these studies have been performed on patients with the early stages of AMD and have evaluated the risk of progression to exudative AMD. Recently, Report 5 of the AREDS 2 Study showed that cataract surgery improved overall mean visual acuity in patients with the different grades of severity of AMD (mild, moderate and severe). ${ }^{6}$ However, this study did not report the retinal and choroidal changes caused by the surgery in patients with neovascular AMD. In an era in which exudative AMD can be treated successfully with anti-vascular endothelial growth factor (VEGF) drugs few studies have addressed cataract surgery in patients being treated with these agents. ${ }^{7-11}$ It is important to understand the effect of cataract surgery and concomitant anti-VEGF therapy on exudative AMD.

Phacoemulsification has been a widely used technique for cataract surgery. It has been linked with worsening of pre-existing retinal diseases such as diabetic macular edema. ${ }^{12-14}$ This deleterious effect of the surgery has been attributed to the release of inflammatory mediators (such as prostaglandins and VEGF) as a result of the surgical aggression. ${ }^{13}$ Several authors have shown that even in patients without retinal pathology, phacoemulsification may lead to a subclinical increase in macular thickness. ${ }^{15-18}$ Since exudative age-related macular degeneration is a vascular endothelial growth factor dependent disease cataract surgery could theoretically lead to a worsening of the CNV if the released VEGF is not antagonized.

Intravitreal anti-VEGF agents such as ranibizumab, ${ }^{19,20}$ bevacizumab $^{21}$ and aflibercept ${ }^{22}$ have been used to treat exudative AND disease with relative success for at least two years.

Some patients with exudative AMD have visually significant cataracts that contribute to their poor visual acuity and require surgery. With simultaneous intravitreal anti-VEGF therapy, the inflammatory insult of cataract surgery may be counteracted by pharmacological activity. Furino et al showed that in eyes with cataract and treatment naïve exudative AMD, a single injection of bevacizumab performed at the end of the surgery improved visual acuity and decreased retinal thickness one month after surgery. ${ }^{10}$ The long-term effects of cataract surgery in patients with established CNV secondary to AMD that are being treated with intravitreal anti-VEGF therapy, have not been extensively studied. Rosenfeld et al showed, in a retrospective analysis of the MARINA and ANCHOR trials that eyes submitted to cataract surgery while on treatment with ranibizumab, increased visual acuity more than 10 ETDRS (Early Treatment Diabetic Retinopathy Study) letters. ${ }^{9}$ This visual acuity gain was maintained for four months. However, the study was not able to evaluate retinal thickness changes induced by surgery or the effect of the surgery on treatment frequencies.

In this study, we evaluated the safety and effectiveness of cataract surgery and simultaneous intravitreal antivascular endothelial growth factor (bevacizumab or ranibizumab) on visual acuity and retinal and choroidal morphology in patients whose exudative AMD had been previously controlled with intravitreal anti-VEGF agents.

\section{MATERIAL AND METHODS}

We conducted a prospective unicentric study at a tertiary care centre, São João Hospital, Porto, Portugal between April 2010 and January 2013. The study protocol was approved by the Ethics Committee of Health of Centro Hospitalar São João and followed the tenets of the Declaration of Helsinki.

Consecutive patients with previously treated exudative AMD proposed to cataract surgery with simultaneous intravitreal anti-VEGF followed for at least one year were eligible for the study.

The following exclusion criteria were considered: baseline best-corrected visual acuity (BCVA) less than $20 / 1000$, other causes of choroidal neovascularization; signs of disease activity at the time of surgery on spectraldomain optical coherence tomography (SD-OCT); myopia greater than 6 diopters; any other retinal vascular disorders; any intra-ocular surgery performed during the study period, including YAG capsulotomy.

In our center, the diagnosis of exudative AMD is made by fundoscopy, fluorescein angiography and SD-OCT using the Spectralis ${ }^{\circledR}$ Heidelberg ${ }^{\circledR}$. Visual acuity was measured using standardized ETDRS charts.

Patients were treated with intravitreal anti-VEGF therapy using a PRN strategy. In this strategy, monthly treatments are performed until there are no signs of choroidal neovascular activity. These signs are based on the PrONTO study ${ }^{23}$ and include the presence of hemorrhage on fundoscopy or the presence of intra-retinal or sub-retinal fluid on SDOCT. When the retinal disease is controlled, patients are followed monthly; treatment is resumed if fundoscopic or OCT disease activity is found on follow-up. After the results of the CATT trial ${ }^{21}$ in May 2011, patients have been treated preferentially with bevacizumab. Before this date, patients were treated with ranibizumab.

Simultaneous cataract surgery and intravitreal bevacizumab/ranibizumab injection was offered to exudative AMD patients when the ophthalmologist observed a cataract that significantly impaired visual acuity and the retina had no intra-retinal or subretinal fluid after intravitreal anti-VEGF therapy. The decision to perform surgery therefore depended on patients' will to have surgery. Due to these subjective criteria, there were differences amongst 
patients in the injection-free time period before surgery. This allowed us to perform a subgroup analysis as we divided the patients into two groups: Group 1 included patients with an injection-free period greater than six months and Group 2 included patients with an injection free period lower than six months.

All cataract surgeries were performed by phacoemulsification (Infiniti ${ }^{\circledR}$ Vision System, Alcon $^{\circledR}$ ) with acrylic intraocular lens implantation in the capsular bag. Cataract surgery and intravitreal injections were performed by two surgeons (MSF and AC).

At the end of the cataract surgery, an intravitreal injection of $1.25 \mathrm{mg}$ of bevacizumab or $0.5 \mathrm{mg}$ of ranibizumab was performed via pars plana. Postoperative medication was the same for all the cases and consisted of dexamethasone, flurbiprofen and ofloxacin eye drops, four times daily for three weeks.

In our analysis, we considered the baseline visual acuity as the visual acuity of the first visit to the clinic. This BCVA was compared to the BCVA before surgery. This was used to redefine BCVA and was compared to visual acuity one month, six months and one year after surgery.

The effect of cataract surgery on central foveal thickness and choroidal thickness was also evaluated. We did not include retinal thickness analysis before the first intravitreal injection as some patients had their initial OCT performed on the Stratus ${ }^{\circledR}$ time domain OCT. In this analysis, we only used central foveal thickness measured using the SD-OCT (Spectralis ${ }^{\circledR}$ ). Manual measurements of the foveal and choroidal thickness were performed on the single horizontal B-scans averaged 100 times, immediately before surgery, one month, six months and one year after surgery. The follow-up function of the Spectralis ${ }^{\circledR}$ was used for all the measurements to ensure that the same locations were evaluated. In a secondary analysis, we compared differences in visual acuity and retinal morphology of the patients in Group 1 and 2. Two investigators (JB and PFC) performed the measurements independently.

Statistical analysis was performed with SPSS statistical package (version 20.0 for Windows; SPSS Inc., Chicago, III., USA). Data was tested for normality and homogeneity of variances. Changes in BCVA and central retinal thickness were evaluated using paired sample t-test. A $p$ value of $<$ 0.05 was considered statistically significant.

\section{RESULTS}

The study included 21 eyes of 20 patients. None of the operated eyes were lost to follow-up during the twelve months. Nine eyes had simultaneous phacoemulsification with ranibizumab and 12 eyes had simultaneous bevacizumab. After the results of the CATT trial ${ }^{21}$ the patients in our department that were being treated with ranibizumab for their exudative AMD were switched to bevacizumab. Only one patient completed the twelve months of followup exclusively with ranibizumab PRN treatment. The mean patient age was 81.3 years (63 - 92). Thirteen patients were females.

Eight patients had an injection free period before cataract surgery greater than six months (Group 1). Of these, three were treated with ranibizumab. Of the remaining 13 eyes in Group 2, six were treated with ranibizumab. There were no intra-operative and perioperative complications. No cases of endophthalmitis or retinal detachments were reported.

\section{Visual outcomes}

The mean baseline visual acuity was $36.0 \pm 21.6$ letters. At the time of cataract surgery, intravitreal therapy had increased mean BCVA by 2.14 letters (not statistically significant, $p=0.495$ ). The cataract surgery associated with intravitreal anti-VEGF led to a statistically significant increase in BCVA of 13.4 letters one month after surgery, 11.5 letters six months after surgery and 11.3 letters one year after surgery ( $p \leq 0.01$ for all time points; Table 1). There were no statistically significant differences in visual acuity changes between patients treated with ranibizumab or bevacizumab (Table 2).

At one month, only 1 patient $(4.7 \%)$ reduced BCVA (five letters); all other eyes improved. Eight eyes (38.1\%) improved up to 10 letters and 12 eyes (57.1\%) improved more than 10 letters.

At twelve months, three eyes had lost letters compared to the pre-operative state: the patient that had lost letters at one month and two others that had had minor improvements at one month (four and seven letters). None of these eyes

Table 1 - Visual acuity, foveal and subfoveal choroidal thickness variation after combined phacoemulsification and intravitreal anti-VEGF

\begin{tabular}{|c|c|c|c|c|c|}
\hline & Baseline & Before surgery & 1 Month & 6 Months & 12 Months \\
\hline $\begin{array}{l}\text { BCVA } \\
(n=21)\end{array}$ & $36 \pm 21.60$ & $38.14 \pm 16.67 \dagger$ & $51.57 \pm 20.95 \dagger$ & $49.67 \pm 18.98 \dagger$ & $48.25 \pm 18.96 \dagger$ \\
\hline $\begin{array}{l}\text { Foveal } \\
\text { thickness } \\
(n=21)\end{array}$ & - & $157.38 \pm 45.11$ & $158.67 \pm 56.04 \ddagger$ & $160.48 \pm 58.36 \ddagger$ & $152.55 \pm 52.33 \ddagger$ \\
\hline $\begin{array}{l}\text { Subfoveal } \\
\text { choroidal } \\
\text { thickness } \\
(n=19)\end{array}$ & - & $171.32 \pm 88.06$ & $177.21 \pm 95.64 \ddagger$ & $177.47 \pm 94.49 \ddagger$ & $178.83 \pm 97.57 \ddagger$ \\
\hline
\end{tabular}

BCVA: Best-corrected visual acuity, measured in ETDRS letters. Foveal and subfoveal choroidal thicknesses are measured in micrometers.

† The improvements in VA one month, six months and 1 year after surgery were statistically significant $(p<0.05)$ when compared to baseline and pre-operative VA.

$\ddagger$ There were no statistically significant changes in foveal and subfoveal choroidal thickness at any of the time points $(p>0.05)$. In two eyes, choroidal measurements were not performed because it was impossible to determine the external choroidal boundary. 
Table 2 - Outcomes comparison between anti-VEGF agent (bevacizumab or ranibizumab)

\begin{tabular}{lccc}
\hline & $\begin{array}{c}\text { Bevacizumab } \\
(\mathbf{n}=\mathbf{1 2})\end{array}$ & $\begin{array}{c}\text { Ranibizumab } \\
(\mathbf{n}=\mathbf{9})\end{array}$ & $\mathbf{p}$ \\
\hline $\begin{array}{l}\text { BCVA variation } \\
\quad \text { Month 1 }\end{array}$ & +14.4 & +12.1 & 0.68 \\
$\quad$ Month 6 & +12.4 & +10.3 & 0.70 \\
$\quad$ Month 12 & +13.7 & +8.2 & 0.35 \\
Foveal thickness & +0.33 & +2.56 & 0.86 \\
Month 1 & & & \\
$\quad$ Subfoveal choroidal thickness & $-0.8 \dagger$ & $+15.1 \mp$ & 0.20 \\
Month 1 & & \\
\hline
\end{tabular}

BCVA: Best-corrected visual acuity, measured in ETDRS letters. Foveal and subfoveal choroidal thicknesses are measured in micrometers. There were no statistically between the two groups in any of the time points. $† \mathrm{n}=11 . \ddagger \mathrm{n}=8$.

lost more than five letters compared to the pre-operative BCVA. The remaining eyes maintained a stable visual acuity gain.

\section{Anatomic outcomes}

One month after the simultaneous phacoemulsification and anti-VEGF injection, there were no significant quantitative changes on the SD-OCT mean foveal thickness; however qualitative changes, namely recurrent intraretinal or subretinal fluid was observed in nine eyes; these eyes were re-injected one month after surgery. At six and twelve months, the slight variations in foveal thickness were not statistically significant either (Table 1).

Two eyes were not included in the choroidal analysis as it was impossible to determine the external limit of the choroid pre-operatively due to opacity of the means. One of the excluded eyes was injected with ranibizumab. Both belonged to Group 2. Of the 19 eyes that were analyzed, no significant changes in choroidal thickness were observed (Table 2).

\section{Subgroup analysis}

The eight patients with a treatment free period greater than six-months (Group 1) increased their visual acuity 8.25 letters ( $p=0.03$ ) whilst the patients in Group 2 increased their visual acuity 16.62 letters $(p=0.01)$, however this difference was not statistically significant $(p=0.13)$. One year after surgery, VA gains were 7.43 and 13.08 letters respectively ( $p=0.45)$ (Table 3$)$.

We did not find any statistically significant changes between the groups in mean foveal thickness one month and one year after surgery. However, of the patients in Group 1, only one resumed bevacizumab injections during the postoperative period. All the 13 patients in Group 2 maintained the need of regular injections throughout the year. However, $33 \%(2 / 6)$ of patients treated with ranibizumab needed retreatment one month after surgery compared to $85 \%(6 / 7)$ of the bevacizumab group. This difference failed to reach statistical significance $(p=0.103)$.

Phacoemulsification did not change the injection rate of the patients in Group 2. Before surgery and after surgery the mean yearly injection rate was 6.0 and 6.2 , respectively.

During follow-up, one of the patients in Group 2 developed a juxtafoveal macular hemorrhage six-months after surgery and four months after the last bevacizumab injection. The hemorrhage slightly decreased BCVA to levels that were higher than the pre-operative evaluation. The patient was treated with monthly bevacizumab injections

Table 3 - Otucomes comparison between Groups 1 (stable disease) and 2 (active disease)

\begin{tabular}{|c|c|c|c|}
\hline & $\begin{array}{c}\text { GROUP } 1 \\
\text { Injection }>6 \text { months } \\
(n=8)\end{array}$ & $\begin{array}{c}\text { GROUP } 2 \\
\text { Injections }<6 \text { months } \\
(n=13)\end{array}$ & $p$ \\
\hline \multicolumn{4}{|l|}{ BCVA } \\
\hline Before surgery & 35.75 & 39.62 & 0.62 \\
\hline Month 1 (variation) & +8.25 & +16.62 & 0.13 \\
\hline Month 12 (variation) & +7.43 & +13.08 & 0.45 \\
\hline \multicolumn{4}{|l|}{ Foveal thickness } \\
\hline Before surgery & 159.98 & 155.85 & 0.85 \\
\hline Month 1 & -1.38 & +2.92 & 0.74 \\
\hline Month 12 & -21.29 & -1.69 & 0.18 \\
\hline \multicolumn{4}{|l|}{ Choroidal thickness } \\
\hline Before surgery & 169.25 & 172.82 & 0.93 \\
\hline Month 1 & -7.50 & +15.6 & 0.054 \\
\hline Month 12 & +1.12 & +9.81 & 0.29 \\
\hline
\end{tabular}

BCVA: Best-corrected visual acuity, measured in ETDRS letters. Foveal thickness is measured in micrometers. There were significant increases in visual acuity (VA) in both groups at 1 month and 12 months after surgery $(p<0.05)$. 
with improvement of the submacular hemorrhage without any further changes in visual acuity.

\section{DISCUSSION}

Cataract surgery on patients with AMD has been widely debated. One large systematic review published in 2008 was unable to determine whether cataract surgery is beneficial or harmful in people with early stages of AMD. ${ }^{2}$ Recently, the AREDS 2 Study showed benefits in all stages of AMD. ${ }^{6}$ Our results show that simultaneous phacoemulsification and intravitreal anti-VEGF therapy in patients with exudative AMD can be beneficial. The visual benefits can be maintained for at least one year if the CNV is managed with a PRN strategy. One month and one year after surgery $95 \%$ and $85 \%$ of patients, respectively, improved BCVA. The visual gains of cataract surgery go beyond visual acuity measurements and include better contrast and color perception.

Our results consolidate the results of other studies..$^{8-11}$ However, we provide a longer follow-up of the patients as well as an SD-OCT evaluation of the retina and choroid throughout the first post-operative year. In this series, the visual acuity gain with phacoemulsification was greater than two Snellen lines, similar to the ones reported in the patients of the MARINA and ANCHOR trials that had surgery ${ }^{9}$; importantly, our results were obtained outside a clinical trial setting. The MARINA and ANCHOR analysis was not able to provide data regarding several critical aspects including: the pre operative retinal condition; the postoperative retinal changes, the time relationship between the anti-VEGF injection (ranibizumab) and the surgery; and, the type of cataract surgery. The data presented included visual acuity results up to four months after the surgery and there is no reference to the percentage of patients that gained or lost vision. Furino et a/10 showed favorable results one month after combined phacoemulsification and bevacizumab in an active exudative AMD setting. Tabandeh et $a^{11}$ reported similar visual acuity gains in a follow-up period that was shorter than twelve months, in patients that had phacoemulsification whilst being treated with either ranibizumab or bevacizumab. Like Tabandeh et al, we included patients that at the time of the cataract surgery procedure were being treated with either ranibizumab or bevacizumab. Clinical trials and clinical setting studies have shown that these drugs have similar results for the treatment of exudative AMD. ${ }^{21,24-26}$ In this specific setting, visual results were also similar for the two drugs.

The sequential retinal follow-up with SD-OCT performed throughout the year allowed us to determine that, if this combined procedure is performed and PRN treatment maintained visual acuity improves without significantly affecting the retinal and choroidal morphology. Thus, the combined procedure does not seem to aggravate the choroidal neovascular exudation.

In our series, the mean BCVA gain from cataract surgery was greater than the visual gain obtained with anti-VEGF therapy alone (> 10 letters versus two letters). The reported visual acuity gains from anti-VEGF therapy in our clinical setting were inferior to the results of clinical trials. ${ }^{19-21}$ This has been previously reported and is attributed to the difficulties in complying with strict follow-up criteria of the trials. ${ }^{27,28}$ However, the fundamental aspect of our results was the significant visual acuity gain obtained from phacoemulsification.

Even though throughout the year there were no significant changes in foveal thickness, we must stress that the qualitative analysis of the SD-OCT is of paramount importance. Criteria of disease reactivation were found on SD-OCT one month after surgery in $43 \%$ of cases. There was a trend showing it to be more frequent in the bevacizumab treated patients. This could be because ranibizumab may be more effective in antagonizing the surgically released VEGF. However, at the end of the study period, the visual acuity benefits were independent of the drug at the time of surgery.

All the patients in Group 2 needed at least one more anti-VEGF injection throughout the year. This shows that active exudation persists after the phacoemulsification, an expected result. However, we did not find a change in retreatment frequencies in the year before and after surgery, suggesting that phacoemulsification 'protected' by the antiVEGF does not alter treatment frequencies. We were not able to compare retreatment rates for the two different drugs as only one patient completed the year of follow-up exclusively on ranibizumab, whilst the others were switched to bevacizumab during follow-up.

Amongst the patients without disease activity for more than six months, only one resumed treatments after surgery. This led us to question the need for a 'prophylactic' anti-VEGF injection in this setting. The authors feel that, in patients who have previously been treated with intravitreal injections, the possible risks of CNV reactivation are greater than the risks of a simultaneous intravitreal injection and that the injection makes sense as a preventive step. However, the answer to this question can only be answered with larger prospective studies.

We did not find any statistically significant changes in choroidal thickness. Exudative AMD is characterized by the loss of the outer blood retinal barrier. In this situation, it could be possible that the ocular inflammatory response to surgery could lead to changes in choroidal thickness. In patients without retinal disease, phacoemulsification does not lead to large variations in choroidal thickness, ${ }^{17,29}$ and in our series we did not find any significant changes in choroidal thickness as far as SD-OCT can measure. This could be either because the inflammatory mediators released into an eye with a damaged external blood retinal barrier do not lead to vascular changes that can be detected by SD-OCT or because the intravitreal anti-VEGF blunts this possible response. Most importantly, the combined procedure does not seem to have a deleterious effect on the choroid.

The final effect of the simultaneous procedure depends on the density of the cataract and on eventual deleterious effects on the retina. Eyes with denser cataracts have a 
greater potential for visual acuity increases. Our study was only performed in patients with visually significant cataracts; probably visual acuity gains in patients with milder cataracts will not be as significant and the decision to perform phacoemulsification should be evaluated case by case.

Overall the procedure was very safe. There were no intra-operative complications caused by the simultaneous procedure and there were no endophthalmitis. The case of subretinal hemorrhage six months after phacoemulsification was not considered a late surgical complication but a case of CNV recurrence. It occurred in an eye that had been without any treatment for four months due to apparent disease stabilization.

In our series we did not have any acute retinal complications such as significant macular edema. However we cannot rule out the possibility that even with a preventive anti-VEGF injection, cataract surgery may precipitate a significant worsening of the macular disease, or even other retinal diseases such as Irvine-Gass syndrome.

From our data we cannot conclude if phacoemulsification by itself worsens CNV because we did not operate patients without the 'protective' effect of anti-VEGF therapy. However, it is known that uneventful phacoemulsification increases retinal thickness in both healthy eyes ${ }^{15}$ and in eyes with diabetic macular edema. ${ }^{12,13}$ Therefore phacoemulsification without a bevacizumab injection in patients with exudative AMD should lead to increased macular thickening and worsening of the retinal disease due to the release of VEGF. In our series, this was probably blunted by the anti-VEGF injection.

The best timing for a bevacizumab injection is debatable. An injection immediately at the end of the phacoemulsification is a good option because it is the time point at which the inflammatory mediators are released into the eye and it will be simultaneously the time point at which the highest concentration of anti-VEGF will be achieved. Furino et al and Jonas et al adopted the same strategy without increased complications. 8,10 Tabandeh et al have advocated an injection 1 - 2 weeks before the surgery; they will probably have the same protective effect, however, a combined intervention is probably less cumbersome for the patient as less visits have to be performed.

We did not study cataract surgery with simultaneous bevacizumab injection in patients with active exudative AMD as Furino et al. ${ }^{10}$ Even though, this study reported visual gains at one month, the long-term results of this approach are unknown.

Since visual acuity gains and retinal thickness stabilization were similar in both Groups 1 and 2, we consider that it is not necessary to maintain a 'dry' retina for a long period of time prior to phacoemulsification. In fact, patients whose disease was not stable showed a nonsignificant greater visual improvement.

One patient lost BCVA one month after surgery, and two more lost BCVA during the first year. This visual loss was not caused by the increase in subretinal or intraretinal fluids and are probably related either to retinal disease progression in the first case or due to posterior capsular opacification (or both) in the latter cases. Nonetheless, visual loss at one year was less than five ETDRS letters.

Our study has several limitations. These include the low number of patients and the absence of a control group. We did not perform potential acuity measurements prior to surgery to estimate the BCVA after surgery.

\section{CONCLUSION}

In conclusion, our results show that simultaneous phacoemulsification and intravitreal anti-VEGF is safe and beneficial in the subset of AMD patients with visually significant cataracts and exudative AMD that has been previously treated. The visual results obtained last for at least one year and no quantitative changes in retinal or choroidal morphology were found. Provided that a close follow-up and correct management of the retinal disease can be obtained, phacoemulsification can be safely performed in these patients, and visual benefits may be expected.

\section{PROTECTION OF HUMANS AND ANIMALS}

The study protocol was approved by the Ethics Committee of Health of Centro Hospitalar São João and followed the regulations established by the Helsinki Declaration of the World Medical Association.

\section{DATA CONFIDENTIALITY}

The authors declare having followed the protocols in use at their working center regarding patients' data publication.

\section{CONFLICTS OF INTEREST}

Manuel Falcão had full access to all the data in the study and takes responsibility for the integrity of the data and the accuracy of the data analysis.

Ângela M. Carneiro has participated in advisory boards for Alimera, Alcon, Bayer and Novartis Pharma.

The other authors have no conflicts of interest to disclose.

\section{FUNDING SOURCES}

This paper received grants from: FCT Portuguese grants from FCT, Lisbon, Portugal (PTDC/SAUORG/110683/2009), through Unidade I\&D Cardiovascular, Porto, Portugal (51/94-FCT).

\section{REFERENCES}

1. Bockelbrink A, Roll S, Ruether K, Rasch A, Greiner W, Willich SN. Cataract surgery and the development or progression of age-related macular degeneration: a systematic review. Surv Ophthalmol. 2008;53:359-67.
2. Casparis H, Lindsley K, Bressler NB. Surgery for cataracts in people with age-related macular degeneration. Cochrane Database Syst Rev. 2009:CD006757.

3. Chew EY, Sperduto RD, Milton RC, Clemons TE, Gensler GR, Bressler 
SB, et al. Risk of advanced age-related macular degeneration after cataract surgery in the Age-Related Eye Disease Study: AREDS report 25. Ophthalmology. 2009;116:297-303.

4. Cugati S, Mitchell P, Rochtchina E, Tan AG, Smith W, Wang JJ. Cataract surgery and the 10-year incidence of age-related maculopathy: the Blue Mountains Eye Study. Ophthalmology. 2006;113:2020-5.

5. Dong LM, Stark WJ, Jefferys JL, Al-Hazzaa S, Bressler SB, Solomon $\mathrm{SD}$, et al. Progression of age-related macular degeneration after cataract surgery. Arch Ophthalmol. 2009;127:1412-9.

6. Age-Related Eye Disease Study 2 Research Group, Huynh N, Nicholson BP, Agrón E, Clemons TE, Bressler SB, et al. Visual acuity after cataract surgery in patients with age-related macular degeneration: age-related eye disease study 2 report number 5. Ophthalmology. 2014;121:122936.

7. Muzyka-Wozniak M. Phacoemulsification in eyes with neovascular AMD treated with anti-VEGF injections. Eur J Ophthalmol. 2011;21:766-70.

8. Jonas JB, Spandau UH, Schlichtenbrede F, Libondi T, Vossmerbaeumer $\mathrm{U}$, von Baltz S. Intravitreal bevacizumab combined with cataract surgery for treatment of exudative macular degeneration. J Ocul Pharmacol Ther. 2007;23:599-600.

9. Rosenfeld PJ, Shapiro H, Ehrlich JS, Wong P. Cataract surgery in ranibizumab-treated patients with neovascular age-related macular degeneration from the phase 3 ANCHOR and MARINA trials. Am J Ophthalmol. 2011;152:793-8.

10. Furino C, Ferrara A, Cardascia N, Besozzi G, Alessio G, Sborgia L, et al. Combined cataract extraction and intravitreal bevacizumab in eyes with choroidal neovascularization resulting from age-related macular degeneration. J Cataract Refract Surg. 2009;35:1518-22.

11. Tabandeh H, Chaudhry NA, Boyer DS, Kon-Jara VA, Flynn HW Jr. Outcomes of cataract surgery in patients with neovascular age-related macular degeneration in the era of anti-vascular endothelial growth factor therapy. J Cataract Refract Surg. 2012;38:677-82

12. Mittra RA, Borrillo JL, Dev S, Mieler WF, Koenig SB. Retinopathy progression and visual outcomes after phacoemulsification in patients with diabetes mellitus. Arch Ophthalmol. 2000;118:912-7.

13. Patel JI, Hykin PG, Cree IA. Diabetic cataract removal: postoperative progression of maculopathy-growth factor and clinical analysis. $\mathrm{Br} \mathrm{J}$ Ophthalmol. 2006;90:697-701.

14. Henriques J, Vaz-Pereira S, Nascimento J, Rosa PC. Doença ocular diabética. Acta Med Port. 2015;28:107-13.

15. Lobo CL, Faria PM, Soares MA, Bernardes RC, Cunha-Vaz JG. Macular alterations after small-incision cataract surgery. J Cataract Refract Surg. 2004;30:752-60.

16. Biro Z, Balla Z, Kovacs B. Change of foveal and perifoveal thickness measured by OCT after phacoemulsification and IOL implantation. Eye.
2008;22:8-12.

17. Falcao MS, Goncalves NM, Freitas-Costa P, Beato JB, Rocha-Sousa A, Carneiro A, et al. Choroidal and macular thickness changes induced by cataract surgery. Clin Ophthalmol. 2014;8:55-60.

18. von Jagow B, Ohrloff $C$, Kohnen T. Macular thickness after uneventful cataract surgery determined by optical coherence tomography. Graefes Arch Clin Exp Ophthalmol. 2007;245:1765-71.

19. Rosenfeld PJ, Brown DM, Heier JS, Boyer DS, Kaiser PK, Chung CY, et al. Ranibizumab for neovascular age-related macular degeneration. $\mathrm{N}$ Engl J Med. 2006;355:1419-31.

20. Brown DM, Kaiser PK, Michels M, Soubrane G, Heier JS, Kim RY, et al. Ranibizumab versus verteporfin for neovascular age-related macular degeneration. N Engl J Med. 2006;355:1432-44.

21. Martin DF, Maguire MG, Ying GS, Grunwald JE, Fine SL, Jaffe GJ. Ranibizumab and bevacizumab for neovascular age-related macular degeneration. N Engl J Med. 2011;364:1897-908.

22. Heier JS, Brown DM, Chong V, Korobelnik JF, Kaiser PK, Nguyen QD, et al. Intravitreal aflibercept (VEGF trap-eye) in wet age-related macular degeneration. Ophthalmology. 2012;119:2537-48.

23. Fung AE, Lalwani GA, Rosenfeld PJ, Dubovy SR, Michels S, Feuer WJ, et al. An optical coherence tomography-guided, variable dosing regimen with intravitreal ranibizumab (Lucentis) for neovascular age-related macular degeneration. Am J Ophthalmol. 2007;143:566-83.

24. IVAN Study Investigators, Chakravarthy U, Harding SP, Rogers CA, Downes SM, Lotery AJ, et al. Ranibizumab versus bevacizumab to treat neovascular age-related macular degeneration: one-year findings from the IVAN randomized trial. Ophthalmology. 2012;119:1399-411.

25. Martin DF, Maguire MG, Fine SL, Ying GS, Jaffe GJ, Grunwald JE, et al. Ranibizumab and bevacizumab for treatment of neovascular age-related macular degeneration: two-year results. Ophthalmology. 2012;119:1388-98

26. Carneiro AM, Mendonca LS, Falcao MS, Fonseca SL, Brandao EM, Falcao-Reis FM. Comparative study of $1+$ PRN ranibizumab versus bevacizumab in the clinical setting. Clin Ophthalmol. 2012;6:1149-57.

27. Gabai A, Veritti D, Lanzetta P. One-year outcome of ranibizumab for neovascular age-related macular degeneration: a thorough analysis in a real-world clinical setting. Eur J Ophthalmol. 2013;24:396-401.

28. Cohen SY, Dubois L, Ayrault S, Dourmad P, Delahaye-Mazza C, Fajnkuchen F, et al. Ranibizumab for exudative AMD in a clinical setting: differences between 2007 and 2010. Graefes Arch Clin Exp Ophthalmol. 2013;251:2499-503.

29. Ohsugi H, Ikuno $Y$, Ohara Z, Imamura H, Nakakura S, Matsuba S, et al. Changes in choroidal thickness after cataract surgery. J Cataract Refract Surg. 2014;40:184-91. 